\title{
MOBILE CARRIER SELECTION IN A POST-CONFLICT ENVIRONMENT - THE PRIMACY OF ETHNICITY OVER CONVENTIONAL NETWORK EFFECTS
}

Tarik Zaimović

\begin{abstract}
In this paper we analyze determinants which affect the selection of mobile carriers in a post-conflict environment - Bosnia and Herzegovina. We apply relevant probability modelling to test perceptions of individual respondents on different network effects obtained through a targeted representative survey. Furthermore, we explore whether some non-traditional influences might affect costumers, focusing on the role of demographic characteristics. Our results confirm that conventional network effects have a role in carrier selection, although they are different across carriers. However, we identify that the ethnicity of respondents overwhelms the traditional network effects by having the highest magnitude in the model. Our findings show that the "ethnic affiliation" of mobile carriers, attributed by the users, remains a persistent factor in attracting and keeping telecommunication costumers in Bosnia and Herzegovina.
\end{abstract}

Keywords: network effects, mobile telecommunications, survey data, ethnicity, logistic regression, Bosnia and Herzegovina

JEL: $M 15,032$

\section{INTRODUCTION}

As information technologies and telecommunications have become irreplaceable parts of our lives in recent decades, the role of network effects has become a subject of intense debate amongst scholars and practitioners. Network effects are a type of externality wherein products or services become more valuable with the greater number of people who use the same or compatible technology, product or service. Therefore, each new network user adds potential value through exchange with other network members (Arthur 1989; Economides 1996). A steady rise in the number of network users increases the total network value for all participants, so a considerable part of overall product value is attributed to the existence of network effects (Arthur 1990). Market winners in a variety of industries, including the telecommunications industry, tend to have these attributes associated with them.

Since the number of network users is assumed to reflect long-term market stability (Katz and Shapiro, 1994), consumers should generally prefer firms with larger installed bases (Shankar and Bayus 2003; Chun and Hahn 2007; Strader et al. 2007). Consequently, it can be especially difficult for newcomers to unseat

Tarik Zaimović, PhD

Assistant Professor

School of Economics and Business

University of Sarajevo

E-mail: tarik.zaimovic@efsa.unsa.ba 
an established rival in markets where the influence of network externalities is strong. Moreover, given the value consumers place on installed base and market dominance, feature-richness and quality may lose in importance - with the result that the "best" product or service does not always win (Farrell and Saloner 1986; Katz and Shapiro 1992; Dranove and Gandal 2003).

Network effects can be viewed as positive externalities and/or as the utility the consumer gains by consuming a good itself, which increases with the number of other persons who consume the same good (Katz and Shapiro 1992). Varian et al. (2004) provides a simple way of looking at network effects, explaining that the value of the membership of one user (in a network) is positively affected by another user who joins and thus increases the network. Church and Gandal (2005) argue that network effects exist if the utility of consumption depends positively on the total number of consumers who buy a compatible product.

The existence of network effects in any particular industry involves new types of market dynamics both for the network users (consumers) deciding to join a network and for manufacturers deciding on production (Goolsbee and Klenow 2002). In their decision to join a network, the consumer will consider network future size, which incentivizes the companies to invest in growing their network- substituting at times in the short term extra profit for long-term success and even a de facto monopoly (Economides 2009). Once the network has been established, markets favor the leading product at the expense of others. It is often a strong lock-in effect, and it raises problems of standardization and interoperability (Farrell and Saloner 1985; Katz and Shapiro 1994; Gruber and Verboven 2001).

Based on the outlines given above, we may easily cite many examples of industries that rely on network effects. In fact, any form of consumption with positive feedback to a similar degree, both on the demand and supply sides, could be understood under the term "network effects" or, if not internalized, "network externalities" (Liebowitz and Margolis 1994). Moreover, such a broad definition makes it difficult to define a uniform set of characteristics of the network, where every user is both a "consumer" and, willingly or not, a "supplier" of the established standard. Still, most authors agree that various forms of network externality significantly affect the consumers' decision to join a given network. When doing so, the consumer in fact considers a series of different direct and indirect network effects - albeit often with a poor understanding of their significance or value (Zaimovic and Avdic 2014).

The aim of this research is to analyze the significance of network effects in the Bosnian and
Herzegovinian (henceforth, $\mathrm{BiH}$ ) telecommunications market. The main question that we investigate is to what extent traditional network effects, including some non-traditional factors, play a role in consumer decision-making and loyalty in a developing telecommunication market. In this analysis we rely on new targeted survey data gathered in $\mathrm{BiH}$. We apply relevant probability modelling in our estimation of the main determinants of consumers' operator choices to join a given network, and while we have identified a number of contemporary network effects, customers by large are still allied to carriers identified as ethnically "theirs". The main contribution of this paper is the finding that ethnicity remains an important determinant in the telecom market of a post-conflict economy and it trumps standard networking effects in terms of its magnitude. This is an important implication that should be considered in future research and by policy makers as well.

In our study, we start with a standard qualitative literature review (Section 1) that discusses the existing findings linked to our study as well as identifies some shortcomings that we aim to address. Next, we explain our research methodology (Section 2) through a description of the data used in empirical modelling and an explanation of our model specification choice. In Section 3 we provide a qualitative interpretation of our findings and continue by discussing the implications of the findings (Section 4) on future research. The last section concludes the paper.

\section{LITERATURE REVIEW}

There is a growing and rather heterogeneous literature focused on the different determinants and dimensions of network effects. For example, Mclntyre and Subramaniam (2009) list 22 empirical studies published over the last 25 years, while Birke (2009) reports a list of 37 research-based works identified over the past 28 years. Given the focus of this paper, we discuss a number of relevant studies in the past ten years. With a more specific focus on mobile telephony, Kim and Kwon (2003) analyze more than 1,000 subscribers of one of the five main South Korean mobile telephony networks. They apply a conditional Logit estimation to determine whether consumers prefer larger mobile networks and conclude that indeed they do ("size effect"), not least because of the discount for calls within the network. The authors also point out that signal or network quality is an additional source of network effects. Fu (2004) had similar finding and also verifies that the install subscriber base is an important factor in Taiwanese consumer's operator choice, and that 
subscriber bandwagon effect is related to on-net/offnet pricing.

On the other hand, Suarez (2005) looks at quarterly data from 177 operators from 47 countries in North and South America between 1992 and 2001. The authors investigate the mobile operators' selection of technology, on one hand, and consider interdependency of selection between the countries on the other hand. Operators were free to choose between three rival standards; the global system for mobile telecommunications, time division multiple access, and code division multiple access. While there is some interoperability between systems and all subscribers can call each other, other important characteristics of the technologies remain incompatible. The author concludes that the mobile operators' choice of technology is not influenced by the total installed base of the given technology, but by the installed base in the countries with which the operator expects the strongest communication ties (traffic). Suarez supports this claim with the finding that gross network size is a relatively poor proxy for network value and that other attributes may be contributing to the benefits of an installed base in network industries. Weitzel et al. (2006) argue that such attributes may include ties between network partners, as well as the density and topology of user networks.

Koski and Kretschmer (2005) present an analysis of 32 industrialized countries between 1991 and 2000 looking at the start-up of the GSM 2 G networks. They conclude that standardization considerably accelerated entry and diffusion of $2 \mathrm{G}$ technology and that price competition within standards is less aggressive than competition between them. More surprisingly, they find that liberalization of fixed line telephony markets itself accelerates commercialization of GSM 2 G networks. Using the same approach, Doganoglu and Grzybowski (2007) measure the impact of network effects on the penetration of mobile telephony into the German market between 1998 and 2003. They find that in the absence of network effects penetration levels for mobile phones would have been at least 50\% lower by the end of the period in focus.

Birke and Swann (2006) provide an overview of the impact of price changes on the structure and volume of traffic. Having analyzed market data for the four largest mobile operators in Great Britain over five years, as well as for 1000 households in three stages, the authors conclude that an additional one percent discount on intra-network calls results in a $0.46 \%$ reduction in the ratio between on- and off-network calls. Interestingly, by using a Multinomial Logit estimation of operator choice, the authors find that each additional family member using the same network has much the same effect on operator choice as an overall increase of 9.2 million in the subscriber numbers for that network. Moreover, Birke, Swann (2006) also demonstrate that household members coordinate their choice of mobile phone carrier, so that, while the mobile phone networks were highly compatible with each other from a technological point of view, network effects were often induced by network operators through higher prices for off-net than for on-net calls. Birke (2008) investigates a large European mobile operator, looking for interdependency between the decision to switch networks and price differentials between on- and off-net calls. Social networks were added as an independent variable to the model. This study identifies that consumers prefer to be in the same network as those they communicate most with. If a co-worker switches to another network, the probability a given individual will also change network doubles. Lower prices for on-net calls can also be an entry barrier to switching networks.

In the extension of their earlier study, Birke and Swann (2010) confirm that the respondents coordinate choice of mobile carrier. They also identify the presence of social networks in carrier selection. This is a similar finding to that of Corrochera and Zirulia (2009); these authors conclude that Italian students who spend more time and pay more attention to the selection of mobile carrier are also those who pay more attention to local network effects and appreciate more operators' selection of their contacts.

In the analysis of the strength of network effects on the Polish market between 1996 and 2001, Grajek (2010) finds that the estimated market size without network effect would have been 15 times smaller than it actually is with network effects. They find that a strong tendency to reduce off-net calls results not just from lower prices for on-net calls, but also from other effects as well, including signal quality and conformist behavior on the part of users. Grajek and Kretschmer (2009) report that user heterogeneity dominates network effects, while different technological generations are complements in terms of usage, but substitutes in terms of subscription. One the other hand, Haucap and Heimeshoff (2011) in their investigation find that consumers may overestimate savings that result from reduced on-net charges and do not correctly incorporate the structure of on-net and off-net calls in their calculations to find optimal tariffs.

In a more recent study, Sobolewski and Czajkowsi (2012) use a multinomial logit model to identify the presence of strong network effects in the Polish mobile market. They attribute these findings to the ratio of the respondents' social group using the same operator and to the strength of on-net price discounts. 
In addition, their finding indicates that the degree of price-based competition between mobile operators is limited by non-price factors, which do contribute to subscribers' choices. Also, Karacuka et al. (2013) analyzes local network effects on operator choice in the Turkish mobile market and relying on a nationwide survey they find close relationship between operator choice and the carrier selection of other people in their local area rather than the overall size of the operator.

Basaran et al. (2014) rely on multinomial and conditional logit estimations to examine the operator choice decisions of subscribers in the Turkish mobile market. They find that overall subscriber base and carriers' pricing strategies are important factors to new subscribers. In addition, their finding further emphasizes that social networks, compared to price or the installed base, have a more significant influence on operator choice and that subscribers that have already selected their carrier are more reluctant to switch because of established contact and the advantages of lower on-net prices. In other words, Basaran et al. (2014) confirm that social network ties, like family, friend or colleagues, are more important in their selection than prices or the overall size of the operator.

Building on the studies presented above, we develop a model for investigating the consumer selection of mobile service providers currently operating in Bosnia and Herzegovina. The mobile service was introduced few years after the Bosnian war (1991-1995). Under the initial mobile provision licensing arrangement (licenses issued in April 2001), all three carriers (BH Telecom, Telecom Srpske and Croatian Telecom) were obliged to provide signal coverage over $80 \%$ of the country's territory by 2004 (including all major cities and roads). BH Telecom was the first one that achieved this goal, in 2003, significantly exceeding the threshold level, and by 2006 all three had met this licensing requirements provision. By 2010, the signal coverage was above $95 \%$ of $\mathrm{BiH}$ territory and all three carriers had offices and sales-points in all the major cities in the country. Moreover, the Communications Regulatory Agency (CRA) had by 2008 introduced a number-portability service, so that by the end of 2012, despite some initial difficulties during introduction, it had become part of the standard service-packages offered by all three mobile carriers. Accordingly, by using the targeted survey data from 2013, we will analyze determinants of costumers' choice and loyalty to its providers.

Considering the post-conflict environment of $\mathrm{BiH}$, it is inevitable to investigate the effect of ethnicity in our modeling, since different ethnic determinants have been already identified as important in much of the empirical (social) research focused on this country (Efendic et al. 2011; Efendic et al. 2014). This is because $\mathrm{BiH}$ is a multicultural country with one of the most 'complicated' ethnic structures in Europe, which has been deepened by a number of problems in the recent past, including the recent Bosnian war.

When BiH was part of ex-Yugoslavia (1945-1992), it was one of the six republics having the highest level of ethnic tolerance (Hodson et al. 1994; Dyrstad 2012). Unfortunately, the war caused a structural break in ethnic composition. This was the period when a multiethnic $\mathrm{BiH}$ went through a radical change from ethnically quite tolerant to quite intolerant in just a few years (Dyrstad 2012). Almost two decades after the war, the country remains highly segregated along ethnic lines, where the three main ethnic groups have substantial autonomy and control over their own ethno-territorial units (Bieber 2010). Ethnic divisions created during the war period have largely been institutionalized by the constitution (Bieber 2006), including initially the telecommunication market as well. Accordingly, the three telecommunications operators were initially organized following ethnic lines established during the war. When establishing their mobile services, signal coverage was also limited to specific areas within $\mathrm{BiH}$. Establishment of the state-level Communication Regulatory Agency eventually produced fierce market competition, especially for urban areas. Nevertheless, our initial research presumption was that the choice of mobile carrier in Bosnia and Herzegovina still reflects the ethnicity of respondents and their being linked to the logic "our" and "their" providers. In the last decade we have seen former state-owned and nationally identified telecom operators (e.g. France, Deutsche, or British telecom) becoming largely global service providers understanding the ethnic, national or racial dimension in carrier selection, which indicates that this social contextualization should receive additional research attention as well. $\mathrm{BiH}$ is a transition and postconflict country, and it is expected that national and ethnic self-identification will still play an important role in everyday life. Accordingly, we believe that $\mathrm{BiH}$ is a good example for assessing this social determinant, which is an interesting point for further investigation; thus in our model we gave special attention to the ethnic identification of respondents.

\section{RESEARCH METHODOLOGY}

\subsection{Sample and data collection}

The research data relates to consumers' decision in selecting one of the three mobile operators in Bosnia and Herzegovina. The survey sample was 2,500 
individuals covering proportionally different entities, regions, municipalities, ethnic groups, gender, as well as urban/rural areas in $\mathrm{BiH}$. The interviews were conducted on a face-to-face basis by a professional agen$c y$. The questionnaire was organized in two sections. In the first part the respondents were asked basic demographic questions, and the second part was composed of 15 questions relevant for this investigation. Descriptive statistics as well as sample demographics are provided in the Appendix'. After excluding respondents who did not use mobile telephones ${ }^{2}$ the sample was reduced to 2,054, which was later used for all estimations. The final sample was $53.8 \%$ males and $46.2 \%$ females, with $61.9 \%$ of respondents from the Federation of $\mathrm{BIH}, 35.2 \%$ from the RS and $2.9 \%$ from the Brčko District. As for self-reported ethnicity, 53.7\% were Bosniaks, $36.1 \%$ Serbs, and $10.1 \%$ Croats. Due to a lack of data from state telecommunication authorities our model is solely based on our cross-section survey.

\subsection{Model specification}

The dependent variable is the mobile carrier choice itself (variables for BH Telecom - "bhtel," Telecom Srpske - "ts" and Croatian Telecom - "ct"). A table with descriptive statistics is presented in the Appendix, while explanations of the controlled variables are detailed below:

- price - in telecommunications markets competition is often reduced to "price" as core competitive and marketing strategy. While product price in network industries has received specific attention in the empirical literature (Birke and Swann 2006; Grajek 2010; Sobolewski and Czajkowsi 2012) it is often seen as a reflection of the value of attractive product features, including a large installed base or adherence to current technological standards (Brynjolfsson and Kemerer 1996; Gallagher and Wang 2002; Gandal et al. 2000 , Srinuan et al. 2012a), or as a strategic variable to be used by the firm to develop its installed base, as a network industry evolves (Ohashi 2003; Chakravarty 2003; Clements and Ohashi 2005). In our model we asked if the price of services was important in the decision to select a

1 Appendix is available at:

http://www.efsa.unsa.ba/ef/docs/Mobile carrier selection Appendix.pdf

2 In our survey $17.9 \%$ of respondents answered that they do not use mobile phones, which corresponds to the official mobile service penetration of $83 \%$ in $\mathrm{BiH}$ published by the state Communication Regulatory Agency at the time of the survey. given operator ${ }^{3}$.

- freemin and bundle - the freemin variable looks at how many free minutes were offered by the various carriers and how this affects consumer selection within the $\mathrm{BiH}$ telecommunications market. The variable bundle controls for how the vendor tailors service packages to meet consumer needs and to what extent the availability and structure of service packages affect carrier selection. These variables are often included as marketing initiatives in mobile carriers' "family plans," "in-network" rates or "free minutes," and are services designed to provide greater value through larger network size (Kim and Kwan 2003; Birke and Swann 2006).

- family and colleague - the family and colleague variables control for how important it is for the consumer to be in the same network as his/her family members and professional colleagues, respectively. Consumers prefer to be in the same network as those they communicate with most (Goolsbee and Klenow 2002; Suarez 2005; Birke and Swann 2006, 2010; Karacuka et al. 2013). Birke (2008) finds that when co-workers switch to another network the probability of a given user changing network as well doubles. The effect is even stronger for family members in the same network. Basaran et al. (2014) confirm that social network ties are more significant in operator selection than prices or the size of the operator.

- size - overall size of the installed base is often attributed to the winner-take-all nature of success in network industries. Companies in network industries - especially in telecommunications - as a matter of principle focus on building up the installed base as quickly as possible, with a view of offering future consumers greater network benefits (Majumdar and Venkatraman 1998; Schilling 2003; Madden et al. 2004). This variable controls for the influence of overall network size, or more precisely said, the overall number of users with a given telecom operator (Shankar and Bayus 2003; Asvanund et al. 2004; Chun and Hahn 2007; Strader et al. 2007) on consumer carrier choice.

- residence - in developing mobile markets, overall network coverage/signal quality (Kim and Kwon 2003) can be the determining factor for

3 Please note that while some authors (e.g. Karacuka et al. 2013; Basaran et al. 2014) use minute-price in standard tariff plan or weighted prices according to respondent's call distribution, due to differences in exiting tariff plans offered by the carriers in $\mathrm{BiH}$, as well as lack of data from CRA, we estimate the importance of price on consumer's carrier selection based on survey data. 
carrier selection. This BiH country specific variable codes at how network coverage in the area of consumers' residence affects carrier selection.

- landline - given the tendency to select mobile carrier based on a pre-existing landline contract - especially during the introductory phase on developing mobile markets (Hausman 2006; Karacuka et al. 2011; Srinuan et al. 2012), we introduce the variable landline in order to investigate the importance of this link.

- no-porta - this variable looks at the extent to which a customer's decision to change service providers is affected by the additional cost incurred, i.e. whether they would change carrier if there were no additional charges and if they could keep their phone number (Liebowitz and Margolis 1995; Shy 2002). The cost of switching is often cited as one of the main elements contributing to a lock-in situation in network markets (Farrell and Klemperer 2007; Srinuan et al. 2012a). In telecommunications, this is often related to the ability to transfer mobile numbers between carriers.

- vas - value added services and complementary products are often considered crucial to network development (Brynjolfsson and Kemerer 1996; Gupta et al. 1999; Gallagher and Wang 2002; Venkartman and Lee 2004; Clements and Ohashi 2005; Duan and Chen 2007). In our model, we looked at how available value added services and the range of complementary products/services impact consumers' decision-making in carrier selection.

- alt_oper - a specific feature in transition and developing telecommunications markets - the coexistence of dominant and emerging "alternative" telecom operators - is often seen as a matter of particular concern for the regulators (Kotski and Kretschmer 2005). In this study, we investigate whether the presence of alternative operators has any impact on the quality of services offered by the dominant operators, and so in turn on user preference in carrier selection.

- quality and crm - service quality and customer relations more generally are frequently cited, albeit not uncontroversially, as the main sources of indirect network effects (Liebowitz and Margolis 1994; Weitzel et al. 2006; Beck et al. 2008). We use the variables quality and $\mathrm{crm}$ to assess the influence of these factors on carrier choice in $\mathrm{BiH}$.

- new_tech - introduction of new technologies is one of the fundamental competitive principles in telecommunications markets. A major driver of key success factors in many, if not most, mobile service markets is the introduction of new technologies (Liikanen et al. 2004), which is more often ascribed to the need to construct a competitive position than to user preference or needs. By including this variable in our model, we explore the impact of technology.

- ethnicity - as explained earlier, because of the post-conflict context of the country, in our model we have paid special attention to a variable that codes different ethnicities. Hence, we control for the self-reported ethnicity status in our modeling procedures following previous research conducted in $\mathrm{BiH}$ (Efendic et al. 2011; Efendic et al. 2014).

- Finally, the traditional individual/demographic variables controlling for gender, age, education, region, and urban/rural are also included in the initial model.

- We estimate our model using binary Logit methodology ${ }^{4}$, which is a multiple regression model applied to a binary dependent variable. We rely on a Logit but not on an OLS estimate because OLS for this binary model is not efficient and the conventional assumptions for the error term do not apply (Heij et al. 2004). However, still it is possible to use a non-linear version of the OLS, but the Maximum Likelihood Estimation technique is easier to use and it has an advantage over OLS because it takes into account the heteroskedasticity of the data (Wooldridge 2006).

Following Wooldridge (2006) our general statement of a binary response model was as follows:

$$
P(y=1 \mid x)=G\left(\hat{\beta}_{1}+\hat{\beta}_{2} x_{2}+\ldots+\hat{\beta}_{k} x_{k}\right)=G(x \cdot \hat{\beta})
$$

The binary dependent variable representing the selection of one of three mobile operators in $\mathrm{BiH}$, where " $\mathrm{x}$ " is the $1 x \mathrm{~K}$ vector of the " $\mathrm{k}$ " independent

variables, " $\hat{\beta}$ " is $K x 1$ vector of the coefficients to be estimated including a constant as the first term (i.e.,

$\left.x \cdot \hat{\beta}=\hat{\beta}_{1}+\hat{\beta}_{2} x_{2}+\ldots+\hat{\beta}_{k} x_{k}\right)$. "G" is a function taking on values between zero and one for all real numbers

"z", i.e., $0 \prec G(z) \prec 1$. " $\operatorname{Pr}(y=1 \mid x)$ " is the probability that the dependent variable takes a value of " 1 " conditional on the given values of the independent variables. In other words, the effect of a particular variable in the model is estimated conditional on the given values of all other independent variables in the

4 Appendix with Logit and Multinomial logit baseline estimations is available at:

http://www.efsa.unsa.ba/ef/docs/Mobile_carrier_selection_Appendix.pdf 
specification, including the constant term. The predicted probabilities are calculated conditional on the set of all explanatory variables. It is not practical to explain how every possible combination of independent variables in the model could affect the predicted probability. However, the most useful outcomes are obtained by calculating marginal changes in the model that provide information on how the outcome probability changes as a particular variable changes from zero to one, holding all other variables constant (Efendic 2010). Since our independent variables in the base specification are binary explanatory variables, then the partial effect (i.e., marginal change - MC) from changing a particular independent variable " $x_{k}$ " from zero to one, holding all other $v$ ariables fixed, is calculated from the following formula:

$$
\begin{aligned}
& M C=G\left(\hat{\beta}_{1}+\hat{\beta}_{2} x_{2}+\ldots+\hat{\beta}_{k-1} x_{k-1}+\hat{\beta}_{k}\right) \\
& -G\left(\hat{\beta}_{1}+\hat{\beta}_{2} x_{2}+\ldots+\hat{\beta}_{k-1} x_{k-1}\right)
\end{aligned}
$$

Since our dependent variable has more than two values, we will also be estimating a Multinomial Logit Model, which is, however, not too different from a binary Logit model, insofar as it estimates separate binary Logit models for each pair of outcome categories (Long and Freese 2006). As estimation of the predicted probabilities again depends on all the explanatory variables in the model, a problem of over-interpretation arises, especially as we are dealing with three possible combinations of results. As with the Logit model, more "useful" information can be obtained by calculating marginal changes. For the Multinomial Logit Model the marginal change calculation is rather complicated (Wooldridge 2006) since it depends

on all the $\hat{\beta}_{k, j \mid J}$ combinations. However, it may be obtained through the following equation (Long and Freese 2006).

$$
\begin{aligned}
& M C=\frac{\partial \operatorname{Pr}(y=m \mid x)}{\partial x_{k}}=\operatorname{Pr}(y=m \mid x) \\
& \left\{\hat{\beta}_{k, m \mid J}-\sum_{j=1}^{J} \hat{\beta}_{k, j \mid J} \operatorname{Pr}(y=j \mid x)\right\}
\end{aligned}
$$

Our baseline results reported below are from the binary Logit estimates since we want to examine the effect of ethnicity for every mobile operator separately. As part of the robustness analysis, we have also estimated models using binary Probit estimation, but the results did not differ with respect to the sign or significance of the estimated coefficients. We reach the same conclusion if we estimate a Multinomial logit model for three possible outcomes.

Following good research practice, we first report the model diagnostics. Both the Likelihood ratio as well as Wald test for all three models reject the null hypothesis at the highest level of significance $(p=0.000)$ that the variables included in the model are jointly equal to zero. We also performed a HosmerLemeshow test, which compares predicted probabilities from the model with the observed data (Long and Freese 2006), providing simple measure of fit. The results do not reject the null hypothesis at any conventional level of significance, and the estimated models for all three operators do fit well. All estimations were implemented in Stata 11 software.

\section{DISCUSSION OF RESULTS}

The following table provides a summary of the baseline results for the three estimated models.

In the initial specification we included standard demographic/individual variables, namely, variables controlling for gender, age, education, region, and urban/rural area. However, none of these variables is significant at conventional levels of statistical significance. Since the model diagnostics proved to be better when we exclude these variables from the model, they are not used in the final specification. It is important to note that the obtained results remain fully consistent in terms of statistical significance, estimated signs and even magnitudes. This checking was part of our robustness procedure and this estimation is available upon request from the author. 
Table 1: The baseline model results for three mobile carriers (marginal effects)

\begin{tabular}{|c|c|c|c|c|c|c|}
\hline & \multicolumn{2}{|c|}{ BH Telecom (bhtel) } & \multicolumn{2}{|c|}{ Telecom Srpske (ts) } & \multicolumn{2}{|c|}{ Croatian Telecom (ct) } \\
\hline & \multicolumn{2}{|c|}{$y=.33466307$} & \multicolumn{2}{|c|}{$y=.49316423$} & \multicolumn{2}{|c|}{$y=.04167889$} \\
\hline & $d y / d x$ & $\mathrm{P}>|\mathrm{z}|$ & $d y / d x$ & $\mathrm{P}>|\mathrm{z}|$ & $d y / d x$ & $\mathrm{P}>|\mathrm{z}|$ \\
\hline price & .0140865 & 0.853 & -.0826943 & 0.348 & .0167330 & 0.288 \\
\hline freemin & .0990555 & 0.132 & -.0791755 & 0.366 & -.0108697 & 0.682 \\
\hline bundle & -.1558778 & 0.008 & .2292977 & 0.000 & -.0202078 & 0.263 \\
\hline family & .0459241 & 0.458 & .0109260 & 0.883 & -.0448478 & 0.163 \\
\hline colleagu & .0926880 & 0.085 & -.1511037 & 0.018 & .0170350 & 0.210 \\
\hline size & .0325199 & 0.424 & -.0616852 & 0.192 & .0081288 & 0.468 \\
\hline residenc & -.1181989 & 0.172 & -.0427972 & 0.610 & .0435347 & 0.000 \\
\hline landline & .1471261 & 0.000 & -.0950502 & 0.046 & -.0367917 & 0.010 \\
\hline no_porta & -.0803368 & 0.045 & .1095778 & 0.024 & -.0058088 & 0.614 \\
\hline vas & -.0692966 & 0.140 & .1838933 & 0.000 & -.0291176 & 0.033 \\
\hline alt_oper & -.0280931 & 0.502 & .0623393 & 0.193 & -.0003097 & 0.978 \\
\hline quality & -.1075267 & 0.177 & .0508576 & 0.555 & .0164984 & 0.236 \\
\hline new_tech & -.1129992 & 0.018 & .0010552 & 0.984 & .0364896 & 0.002 \\
\hline $\mathrm{crm}$ & -.0678995 & 0.342 & .1349609 & 0.084 & -.0093271 & 0.657 \\
\hline bosniacs & \multicolumn{2}{|c|}{ omitted $^{5}$} & -.8106514 & 0.000 & -.2732839 & 0.000 \\
\hline serbs & -.7322741 & 0.000 & \multicolumn{2}{|c|}{ omitted } & -.1899129 & 0.000 \\
\hline croats & -.3820513 & 0.000 & -.5789735 & 0.000 & \multicolumn{2}{|c|}{ omitted } \\
\hline
\end{tabular}

\begin{tabular}{|c|c|c|c|}
\hline & BH Telecom (bhtel) & Telekom Srpske (ts) & Croatian Telecom $(c t)$ \\
\hline Number of obs. & $=1,519$ & $=1,519$ & $=1,519$ \\
\hline Likelihood ratio test & $\begin{array}{l}\operatorname{chi} 2(17)=1006.21 \\
\text { Prob }>\text { chi } 2=0.0000\end{array}$ & $\begin{array}{l}\text { chi } 2(17)=1025.92 \\
\text { Prob }>\text { chi } 2=0.0000\end{array}$ & $\begin{array}{l}\text { chi } 2(17)=394.76 \\
\text { Prob }>\text { chi } 2=0.0000\end{array}$ \\
\hline Wald test & $\begin{array}{l}\operatorname{chi} 2(17)=458.28 \\
\text { Prob }>\text { chi2 }=0.0000\end{array}$ & $\begin{array}{l}\text { chi } 2(17)=480.10 \\
\text { Prob }>\text { chi2 }=0.0000\end{array}$ & $\begin{array}{l}\text { chi } 2(17)=282.00 \\
\text { Prob }>\text { chi } 2=0.0000\end{array}$ \\
\hline Hosmer-Lemeshow test & $\begin{array}{l}\operatorname{chi} 2(8)=10.17 \\
\text { Prob }>\text { chi } 2=0.2531\end{array}$ & $\begin{array}{l}\operatorname{chi} 2(8)=9.80 \\
\text { Prob }>\text { chi } 2=0.2795\end{array}$ & $\begin{array}{l}\operatorname{chi} 2(8)=6.69 \\
\operatorname{Prob}>\text { chi2 }=0.5704\end{array}$ \\
\hline
\end{tabular}

We start our discussion with the results obtained for the standard network determinants in the model. There is only one significant variable for all three estimated models - the variable landline. Assuming no change in the other parameters, consumers of $\mathrm{BiH}$ Telecom value the link between mobile and landline carrier and select BH Telecom over the other two carriers (15\% higher probability). Since BH Telecom still maintains a leadership position in major urban areas and business centers ${ }^{6}$ this result is not surprising.

5 In each model the ethnic variable with significant correlation has been omitted from the presented results. In the case of $\mathrm{BH}$ Telecom this variable is "Bosniaks", for Telecom Srpske "Serbs" and for Creation Telecom "Croats".

6 The Penetration level for landline telephony in households is estimated at $80 \%$ (CRA 2013).
Accordingly, this mobile carrier exploits the "landline link" locking-in customers to affordable and integrated service packages ${ }^{7}$. On the other hand, this variable is significant but negative for the other two carriers, hence suggesting an antipodal valuation of the landline variable. This to a certain extent can be attributed to the shifting corporate policies of Telecom Srpske and Croatian Telecom towards the largest competitors' market (BH Telecom) and thus services offered to customers have to be designed without relying on an existing consumer-base.

7 Integrated services (Dual, Triple or Quadruple) in telecommunications is a term for providing service over a single broadband connection: exp. broadband Internet access, television, telephone and discriminatory pricing for selected mobile numbers. 
Next to landline, the variable bundle and no_porta are statistically significant for two direct market competitors - BH Telecom and Telecom Srpske, but with different signs. In other words, ceteris paribus, consumers are less likely to select BH Telecom as their mobile carrier, if they value a service-package customization (bundle, $-16 \%$ ) or can switch carrier without additional cost (no_port, -8\%) while keeping their phone number. Contrary to BH Telecom, in the Telecom Srpske model the bundle variable has a positive effect (22\%), giving Telecom Srpske a lead amongst customers who value service-package customization. The obtained coefficient on the no_porta variable (estimated at the border line of significance) indicates that number portability and switching costs are to a certain extent issues to consider in carrier selection among the users of Telecom Srpske (11\%).

In looking at variables significant for a particular carrier in the $\mathrm{BH}$ Telecom model, the variable new tech indicates that the consumers are less likely $(-11 \%)$ to select BH Telecom as their mobile carrier if they value new technology and solutions offered. Opposed to this is the finding for Croatian telecom; the new_tech variable is both significant and positive in sign, so even though the value for marginal effects are rather small (4\%), it does indicate that customers are more likely to select Croatian Telecom as their carrier if they value new technologies and services. Furthermore, we find that the customers who value value-added services - vas - and complementary products are more likely to join the Telecom Srpske network (18\% higher probability). Additionally, the significance of colleague variable reveals additional decision-making preferences, indicating a lack of importance of social ties in carrier selection. Consumers are less likely to select Telecom Srpske as their mobile carrier $(-15 \%)$ if they place little importance on social networking with colleagues from work. On the other hand, this variable is positive (9\%) for BH Telecom customers, confirming the importance of social ties in the selection of BH Telecom.

Finally, bearing in mind post-war realities in $\mathrm{BiH}$, it was important to investigate whether ethnicity plays a significant role in consumer decision-making. The results do suggest that almost 20 years after the war ethnicity still plays an important role. In all three models, the variable that codes ethnicity of the respondent is significant at the highest level $(p=0.000)$, with very high marginal effects and negative signs for carriers considered to belong to "other ethnicity" (i.e. not the respondent's ethnicity ${ }^{8}$ ). Looking at the results for $\mathrm{BH}$

8 As expected, we observed a relationship between the carriers and the associated ethnicity based on the predominant consumer base and ethnic majority territory. For BH Telecom, this are Bosniaks; for Telecom Srpske, Serbs; and for Croatian Telecom,
Telecom (dominant in the majority Bosniak areas), the results suggest that in $73 \%$ cases the Serbs and in $38 \%$ cases the Croats are less likely to select BH Telecom as their mobile carrier in comparison to Bosniaks. Similar results are obtained for Telecom Srpske (dominant in majority Serb areas) - there is $81 \%$ smaller probability that Bosniaks and $58 \%$ smaller probability that the Croats are likely to select Telecom Srpske as their carrier. Finally, for Croatian Telecom it is less likely by $19 \%$ that Serbs and less likely by $27 \%$ that Bosniaks are going to choose Croatian Telecom (dominant in the Croatian majority area) as their mobile carrier in comparison to Croats.

\section{RESEARCH IMPLICATIONS}

Although we identify the importance of standard network effects in our research, we find that consumers' ethnic self-reported identity plays an important role in carrier selection. The effect of ethnicity is the "best identified" in terms of significance, "consistent" sign and magnitude for all three operators. However, we find that control variables associated with more contemporary network effects remain important. For example, the link between landline operator and mobile carrier (the landline variable) remains significant for all three operators 9 . The variable is positive for the largest telecom operator - BH Telecom - since consumers value the benefits of having a large network in both landline and mobile communications, as well as coverage in the biggest urban areas in the country. The negative sign comes as something of a surprise for Telecom Srpske since this is the second largest operator in the country providing landline services to a large network of households and businesses. Here the lack of importance of the landline-mobile link for Telecom Srpske users can be attributed to the fact that the operator was recently privatized and has conducted a persuasive and aggressive marketing campaign in the areas where they traditionally do not have a large user base. This has been accompanied with a steep increase in the number of mobile service users obviously not valuing the link with their landline service providers. The case is similar for Croatian Telecom, whose installed user base is the smallest with regard to both landline and mobile service provision, so that the association with landline provision, although significant, is negative. This to a certain extent confirms that these two operators have "won-over" customers in

Croats. In our estimations for each model we omitted these specific variables and focused on the two other ethnicities.

9 At present, all three operators provide both landline and mobile services. 
the territories they cover, so that their goal is now to make inroads into the $\mathrm{BH}$ Telecom market and develop their strategies for attracting customers.

Our research indicates that respondents are the most critical towards the largest operator and we find as many as three variables with a negative sign. Thus, whether customers base their operator choice on the customer packages being offered in mobile telephony - bundle (-16\%), or on the ability to transfer their number-no_port (-8\%), or indeed new technology - new_ tech $(-11 \%)$, or on any of the other fixed parameters, they are less likely to choose BH Telecom than the other two operators. A number of reasons could be given for these results, but the fact is that BH Telecom covers largely urban areas; has a customer base with probably the highest educational profile; and is by far the largest and more advanced carrier - its customer expectations are rather high and thus are more critical.

With regard to Telecom Srpske, it is particularly interesting that the two variables that were negative for the largest competitor, namely bundle and no_port, are positive. Indeed, for customers for whom the mobile service packages being offered (23\%) as well as number portability without additional cost $(11 \%)$ are of main concern, the Telecom Srpske is the more likely choice. Moreover, the only negative variable for Telecom Srpske is the variable relating to consumers' social ties, or in our case whether the operator is being used by friends or colleagues from work. Interestingly, this variable is opposite in sign to that of its biggest competitor (BH Telecom) as this value is negative for Telecom Srpske (-15\%), while for BH Telecom it is positive $(9 \%)$. This all suggests that Telecom Srpske's business policy is clearly directed toward market competition, with its biggest competitor aggressively pursuing BH Telecom's consumers.

$\mathrm{BH}$ Telecom should also be worried by the fact that all the indicators from the descriptive statistics show a comparative relationship between $\mathrm{BH}$ Telecom and Telecom Srpske as two directly competing operators. Also, customers particularly value aforementioned services (bundle and no_port) for which $\mathrm{BH}$ Telecom has negative values and scores worse than the other two carriers. Among the three carriers, customers who responded in the survey that they value service packages offered by the carrier $(-16 \%)$ and number portability without additional cost $(-8 \%)$, are less likely to select $\mathrm{BH}$ telecom as their carrier.

In looking at the results presented above, we have seen that consumers pay little attention to service price and do not correctly asses the structure in their calculations to find optimal tariffs, to some extent confirming the findings of Grajek (2010) as well as Sobolewski and Czajkowsi (2012). Also, our findings have confirmed those of Karacuka et al. (2013), that carrier selection is closely related to other people in their local area carrier choice, rather than the overall size of the operator or price. Finally, our findings clearly show that social networks, compared to price or the installed base, have more significant influence on operator choice, confirming the findings of Birke (2008) and Basaran et al. (2014).

Thus far, in available research, we have seen the use of a number of traditional control variables (e.g. gender, age, education, rural/urban, etc.) while to our knowledge, the ethnicity of the respondents has been neglected. In the case of $\mathrm{BiH}$, because the service provision by mobile carriers has been countrywide for almost a decade, we considered it important to assess whether perceptions of their ethnic self-assessment have influenced carrier selection and to what extent. In spite of the long list of positive trends evident from the preceding analysis, our model indicates clearly that the variable coding ethnicity still represents a rather significant factor in the model. A particularly strong association between the variables representing ethnic self-assessment and choice of carrier confirms that the majority of respondents still view either directly or indirectly (we cannot make this distinction) the carriers as representing ethnic categories. In other words, the respondents are still more inclined to choose or to stay with a mobile carrier perceived as "their own," while not ignoring conventional network effects. Although limited to a post-conflict country, this study provides a look at carrier selection while assessing the influence of the ethnic dimension of respondents. Understanding ethnic, national or racial dimensions in service provision in today's social context should receive much more attention, and with the changing social and ethnic landscape in Europe the findings presented in this study could serve as an initial look at possible challenges ahead.

\section{CONCLUSIONS}

In this paper we analyze the role of network effects in mobile service provision in $\mathrm{BiH}$ by relying on respondents' (consumers) perceptions. While we identify a number of contemporary network effects, especially in relations between the two direct market competitors (BH Telecom and Telecom Srpske), by in large the customers are still overwhelmingly allied to the operators identified as belonging to their ethnicity. Controlling for other variables, the ethnicity of the respondents clearly shows a particularly important and strong influence when it comes to the selection of "ethnically suitable" carrier, as well as negative values for the "other" two carriers. Apparently, ethnicity 
remains an important determinant in this market and trumps standard networking effects in terms of magnitude. We believe that this is the main contribution of this paper and that it applies more generally to postethnic-conflict societies.

Network effects remain an important aspect of antirust and regulatory analyses in mobile services as they directly influence consumer' decision to opt for a carrier. What we have seen from our study is that a traditional network effect, for example price or network size, is not perceived by users as important, and that market dynamics rely on a different set of pertinent issues. The link between landline and mobile service provision has a significant effect for all three estimated models, but with different signs. This link is significant and positive for users of the largest telecom operator in the country (BH Telecom). Interestingly, when customers base their operator choice on the quality of service packages being offered or the ability to transfer their number to a different carrier, they prefer Telecom Srpske (the second largest carrier), confirming to a certain extent that the development of better quality customer packages has resulted in attracting customers who are slowly losing sight of carrier "national prefix". Consequently, we have seen Telecom Srpske (now renamed to: "m:tel") gradually making inroads into the Federation of $\mathrm{BiH}$ market, particularly the $\mathrm{BH}$ Telecom market. In all, attributing dramatic changes in demand for telecommunication services only to price competition (a significant drop in end-user prices in practically all telecommunication services), and by ignoring network effects, could result in misaligned competitiveness strategies and overall approaches to consumers (Zaimovic et al. 2015).

Although we do find some of the contemporary network effect to be significant in the mobile carrier market, the values associated with the variable that codes ethnicity lead us to conclude that the choice of carrier is still largely based on the ethnic identification of the individual carriers as "ours" - which in itself, at least for Bosnia and Herzegovina, could now be viewed as a network associated externalities.

Finally, we would like to mention some of the limitations of this research. First, we base our research on survey data, which means that we are working with perceptions of respondents but not on measurable outputs or their real decisions. Accordingly, what people say is not necessarily something they do; their answers might be subjective and contain perception bias. Still, personal opinions are welcomed and interesting simply because people are the best judges of their own interests and their views are often more relevant than opinions of some high experts, planning authorities and even some statistical indicators (Efendic and Pugh 2015). Bearing in mind this is a cross-section survey, the time dimension and potential timing effects in the model remains to be explored. The model specification was built on a theory including some country-specific determinants, but always some new determinants might be relevant to explore, including other methodologies. In particular, it might be interesting to explore potential endogeneity caused by the simultaneity of some networking effects, which we cannot address at this time.

For future research it could be interesting to further explore the effect of ethnicity in the model by estimating multi-level models based on location of respondents or the structure of different groups within the same ethnicity. It could be important to control for ethnic diversity at the local level and its effect in the model, as well as other post-conflict determinants (e.g. the war (e)migrant status, international migration experience, including some interaction effects). In addition, considering the presented findings, although limited to the context of $\mathrm{BiH}$, understanding the ethnic, national or racial dimension in service/product selection in today's social context should receive more attention. Also, in the recent decade we have seen a number of state-owned telecom operators making investments in rebranding and market re-profiling, shifting away from their initial image to a more "generic one" (e.g Deutsche telecom to t-com or France Telecom to Orange, etc.). Following findings presented in this study, assessing possible changes in consumers' carrier choice in EU countries - provided that they are familiar with operator history and pre-rebranding title - might provide an interesting new perspective on consumers' carrier decisions. Finally, replication of this study in other post-conflict environments, especially in the South-East European region, is welcomed, as well as retesting these results in $\mathrm{BiH}$ with the inclusion of a dynamic component. 


\section{REFERENCES}

Arthur, W.B. 1989. Competing technologies, increasing returns, and lock-in by historical events, Economic Journal 99: 116-131.

Arthur, W.B. 1990. Positive feedbacks in the economy, Scientific American February: 92-99.

Asvanund, A., Clay, K.; Krishnan, R., Smith, M.D. 2004. An empirical analysis of network externalities in peer-to-peer music-sharing networks, Information Systems Research 15(2): 155-174.

Basaran, A., Cetinkaya, M., Bagdadioglu, N. 2014. Operator choice in the mobile telecommunications market: Evidence from a Turkish urban population, Telecommunications Policy 38: 1-13.

Beck, R., Beimborn, D., Weitzel, T., König, W. 2008. Network effects as drivers of individual technology adoption: Analyzing adoption and diffusion of mobile communication services, Information Systems Frontiers 10: 415-429

Bieber, F. 2006. Post-war Bosnia: Ethnicity, Inequality and Public Sector Governance, Basingstoke: Palgrave Macmillan.

Bieber, F. 2010. Bosnia and Herzegovina since 1990, in Ramet, S. (ed.), Central and Southeast European Politics Since 1989, Cambridge: Cambridge University Press, pp. 311-328

Birke, D. 2008, Diffusion on networks: modelling the spread of innovations and customer churn over social networks, in N. Gronau and C. M“uller (eds), Bildung von sozialen Netzwerken in Anwendungen der Social Software. Berlin: GITO Verlag.

Birke, D. 2009. The economics of networks: A survey of the empirical literature, Journal of Economics Surveys 23(4): 762-793.

Birke, D., Swann, G.M.P. 2006. Network effects and the choice of mobile phone operator, Journal of Evolutionary Economics 16(1-2): 65-84.

Birke, D., Swann, G.M.P. 2010. Network effects, network structure and consumer interaction in mobile telecommunications in Europe and Asia, Journal of Economic Behavior and Organization 76(2): 153-167.

Brynjolfsson, E., Kemerer, C.F. 1996. Network externalities in microcomputer software: an econometric analysis of the spreadsheet market, Management Science 42(12): 1627-1647.

Chakravarty, S. 2003. Experimental Evidence on Product Adoption in the Presence of Network Externalities, Review of Industrial Organization 23: 233-254

Chun S.Y., Hahn M. 2007. Network externality and future usage of Internet service, Internet Research 17(2): 156-168.

Church, J., Gandal N. 2005. Platform Competition in Telecommunication, Handbook of telecommunications economics, Elsevier 2: 119-153.
Clements, M.T., Ohashi, H. 2005. Indirect network effects and the product cycle: video games in the US, 1994-2002, Journal of Industrial Economics 53(4): 515-542.

Corrocher, N., Zirulia, L. 2009. Me and you and everyone we know: An empirical analysis of local network effects in mobile communications, Telecommunications Policy 33(1-2): 68-79

CRA, 2013. State Commination Regulatory Agency-CRA Annual Report for 2013

Doganoglu, T., Grzybowski, L. 2007. Estimating network effects in mobile telephony in Germany, Information Economics and Policy 19(1): 65-79.

Dranove, D., Gandal, N. 2003. The DVD-vs.-DIVX standard war: empirical evidence of network effects and preannouncement effects, Journal of Economics and Management Strategy 12(3): 363-386.

Duan W., Chen Y. 2007. Key Factor to Drive Success of New Product with Network Effects: Product Quality or Installed Base? Systems Engineering - Theory \& Practice 27(7): 144-148

Dyrstad, K. 2012. After ethnic civil war: Ethno-nationalism in the Western Balkans, Journal of Peace Research 49(6): 817-831.

Economides, N. 1996. The economics of networks, International Journal of Industrial Organization 14(6): 673-699.

Economides, N. 2009. Networks, Telecommunication Economics, and Digital Convergence, Notes on Network Economics - MBA class

Efendic, A. 2010. Institutions and economic performance in transition countries, LAP Lambert Academic Publishing

Efendic, A., Mickiewicz, T., Rebmann, A. 2014. Growth aspirations and social capital: young firms in a post-conflict environment, International Small Business Journal 33(5): 537-561.

Efendic, A., Pugh, G. 2015. Institutional effects on economic performance in transition: a dynamic panel analysis, Acta Oeconomica 4/2015

Efendic, A., Pugh, G., Adnett, N. 2011. Confidence in formal institutions and reliance on informal institutions in $\mathrm{BiH}$ : An empirical investigation using survey data, Economics of Transition 19(3): 521-540.

Farrell, J., Klemperer, P. 2007. Coordination and Lock-in: Competition with switching cost and network effects, Handbook of Industrial Organization 3: 1967-2072.

Farrell, J., Saloner, G. 1985. Standardization, compatibility, and innovation, Rand Journal of Economics 16(1): 70-83.

Farrell, J., Saloner, G. 1986. Installed base and compatibility innovation, product preannouncements and predation, American Economic Review 76(5): 940-955.

Farrell, J., Saloner, G. 1992. Converters, Compatibility, and the Control of Interfaces, The Journal of Industrial Economics, Vol. XL 
Fu, W.W. 2004. Termination-discriminatory pricing, subscriber bandwagons, and network traffic patterns: the Taiwanese mobile phone market, Telecommunications Policy 28(1): 5-22.

Gallaugher, J., Wang, Y. 2002. Understanding network effects in software markets: Evidence from Web server pricing, MIS Quarterly 26: 303-327.

Gandal, N., Kende, M., Rob, R. 2000. The Dynamics of Technological Adoption in Hardware/Software Systems: The Case of Compact Disc Players, RAND Journal of Economics 31: 43-61

Goolsbee, A., Klenow, P.J. 2002. Evidence on learning and network externalities in the diffusion of home computers, Journal of Law and Economics 45(2): 317-343.

Grajek, M. 2010. Estimating network effects and compatibility: Evidence from the Polish mobile market, Information Economics and Policy 22(2): 130-143.

Grajek, M., Kretschmer T. 2009. Usage and diffusion of celIular telephony 1998-2004, International Journal of Industrial Organization 27(2): 238-249.

Gruber, H., Verboven, F. 2001. The evolution of markets under entry and standards regulation - the case of global mobile telecommunications, International Journal of Industrial Organization 19(7): 1189-1212.

Gupta S., Dipak C. J., Sawhney M.S. 1999. Modeling the Evolution of Markets with Indirect Network Externalities: An Application to Digital Television, Marketing Science 18(3): 396-416.

Haucap, J., Heimeshoff, U. 2011. Consumer behavior towards on-net/off-net price differentiation. Telecommunications Policy 35, 325-332.

Hausman, J. 2006. Mobile telephone, Handbook of telecommunications economics, Elsevier 1: 563-604

Heij, C., de Boer, P., Franses, P. H. and van Dijk, H. K. 2004. Econometric Methods with Applications in Business and Economics, Oxford: Oxford University Press.

Hodson, R., Sekulic, D., Massey, G. 1994. National tolerance in the former Yugoslavia, American Journal of Sociology 99(6): 1534-1558.

Huang, C.I. 2010. Intra-household effects on demand for telephone service: Empirical evidence, Quant Mark Econ 11: 231-261

Karacuka, M., Çatik, A. N., Haucap, J. 2013. Consumer choice and local network effects in mobile telecommunications in Turkey, Telecommunications Policy 37: 334-344.

Karacuka, M., Haucap, J., Heimeshoff, U. 2011. Competition in Turkish mobile telecommunications markets: Price elasticities and network substitution, Telecommunications Policy 35(2): 202-210.

Katz, M.L., Shapiro, C. 1992. Product introduction with network externalities, The Journal of Industrial Economics 11(1): 55-83.
Katz, M.L., Shapiro, C. 1994. Systems competition and network effects, Journal of Economic Perspectives 8(2): 93-115.

Kim, H.S., Kwon, N. 2003. The advantage of network size in acquiring new subscribers: a conditional logit analysis of the Korean mobile telephony market, Information Economics and Policy 15(1): 17-33.

Koski, H., Kretschmer, T. 2005. Entry, standards and competition: firm strategies and the diffusion of mobile telephony, Review of Industrial Organization 26(1): 89-113.

Liebowitz, S., Margolis, S. 1994. Network externality - an uncommon tragedy, Journal of Economic Perspectives 8(2): 133-150.

Liebowitz, S., Margolis, S. 1995. Path dependence, lock-in, and history, Journal of Law, Economics, and Organization 11: 205-226.

Liikanen, J.,Stoneman, P.,Toivanen, O.2004.Intergenerational effects in the diffusion of new technology: the case of mobile phones, International Journal of Industrial Organization 22(8-9): 1137-1154.

Long, S.J., Freese, J. 2006. Regression Models for Categorical Dependent Variables Using Stata, Second Edition, Texas: A State Press Publication.

Madden, G., Coble-Neal, G.; Dalzell, B. 2004. A dynamic model of mobile telephony subscription incorporating a network effect, Telecommunications Policy 28(2): 133-144.

Majumdar, S., Venkatraman, S. 1998. Network effects and the adoption of new technology: Evidence from the U.S. telecommunications industry, Strategic Management Journal 19: 1045-1062.

Mclntyre, D., Subramaniam, M. 2009. Strategy in Network Industries: A Review and Research Agenda, Journal of Management 35(6): 1494-1517.

Ohashi, H. 2003. The role of network effects in the US VCR market, 1978-1986, Journal of Economics and Management Strategy 12(4): 447-494.

Schilling, M. 2003. Technological leapfrogging in the U.S. video game console industry, California Management Review 45: 6-32.

Shankar, V., Bayus, B. 2003. Network effects and competition: An empirical analysis of the home video game industry, Strategic Management Journal 24: 375-384.

Shy, O. 2002. A quick-and-easy method for estimating switching costs, International Journal of Industrial Organization 20: 71-87.

Sobolewski, M., Czajkowsi, M. 2012. Network effects and preference heterogeneity in the case of mobile telecommunications markets, Telecommunications Policy 36: 197-211.

Srinuan P., Srinuan C., Bohlin E. 2012. Fixed and mobile broadband substitution in Sweden. Telecommunications Policy 36 (3): 237-251. 
Srinuan, P., Bohlin, E., Madden, G. 2012a. The determinants of mobile subscriber retention in Sweden. Applied Economics Letters 19 (5): 453-457.

Strader T.J., Ramaswami S.N., Houle, P.A. 2007. Perceived network externalities and communication technologies acceptance, European Journal of Information Systems 16: 54-65.

Suarez, F. 2005. Network effects revisited: the role of strong ties in technology selection, Academy of Management Journal 48(4): 710-720.

Varian, H.R., Farrell J., Shapiro C. 2004. The Economics of Information Technologies, Cambridge University Press

Venkatraman, N., Lee, C. 2004. Preferential linkage and network evolution: A conceptual model and empirical test in the U.S. video game sector, Academy of Management Journal 47: 876-892.

Weitzel, T., Beimborn, D., Konig, W. 2006. A unified economic model of standard diffusion: The impact of standardization cost, network effects, and network topology, MIS Quarterly 30: 489-514.

Wooldridge, J. M. 2006. Introductory Econometrics A Modern Approach, Third Edition, Mason: Thomson South-Western.

Zaimović T., Zaimović A., Mustafić A. 2006. Bosnia and Herzegovina telecommunication sector outlook, Procedia - Social and Behavioral Sciences 195: 82-92

Zaimovic T., Avdic A. 2014. Review of the selected empirical papers in network economy, Sarajevo Business and Economics Review 33: 73-100. 